\title{
SARS-CoV-2 Omicron variant virus isolates are highly sensitive to interferon treatment
}

Running title: High interferon sensitivity by Omicron viruses

Denisa Bojkova ${ }^{1}$, Tamara Rothenburger ${ }^{1}$, Sandra Ciesek $^{1,2,3}$, Mark N. Wass ${ }^{4 *}$, Martin Michaelis $^{4 *}$, Jindrich Cinatl jr. ${ }^{1,5 *}$

${ }^{1}$ Institute for Medical Virology, University Hospital, Goethe University, Frankfurt am Main, Germany

${ }^{2}$ German Center for Infection Research, DZIF, External partner site, Frankfurt am Main, Germany

${ }^{3}$ Fraunhofer Institute for Molecular Biology and Applied Ecology (IME), Branch Translational Medicine und Pharmacology, Frankfurt am Main, Germany

${ }^{4}$ School of Biosciences, University of Kent, Canterbury, UK

${ }^{5}$ Dr. Petra Joh-Forschungshaus, Frankfurt am Main, Germany

* Corresponding authors:

Jindrich Cinatl jr., Institute for Medical Virology, University Hospital, Goethe University, Paul Ehrlich-Straße 40, 60596 Frankfurt am Main, Germany; phone +49 696301 6409; e-mail Cinatl@em.uni-frankfurt.de

Martin Michaelis, School of Biosciences, University of Kent, Canterbury CT2 7NJ, UK; phone +44 122782 7804; e-mail M.Michaelis@kent.ac.uk

Mark N. Wass, School of Biosciences, University of Kent, Canterbury CT2 7NJ, UK; phone +44 122782 7626; e-mail M.N.Wass@kent.ac.uk 


\begin{abstract}
Recently, we have shown that SARS-CoV-2 Omicron virus isolates are less effective at inhibiting the host cell interferon response than Delta viruses. Here, we present further evidence that reduced interferon-antagonising activity explains at least in part why Omicron variant infections are inherently less severe than infections with other SARS-CoV-2 variants. Most importantly, we here also show that Omicron variant viruses display enhanced sensitivity to interferon treatment, which makes interferons promising therapy candidates for Omicron patients, in particular in combination with other antiviral agents.
\end{abstract}


The SARS-CoV-2 Omicron variant (B.1.1.529) causes less severe disease than previous SARS-CoV-2 variants, although immune protection provided by vaccinations and previous infections is reduced against Omicron compared to previous variants [14]. In agreement, evidence is emerging that Omicron is inherently less pathogenic than previous SARS-CoV-2 variants. Omicron variant viruses cause less severe disease in animal studies [5-7] and Omicron viruses appear to display a lower capacity than other variants to replicate in the lower respiratory tract $[7,8]$. Additionally, initial clinical data indicated that the Omicron variant causes less severe disease than previous SARSCoV-2 variants in unvaccinated individuals [3].

We have most recently shown that Omicron variant viruses are less effective at antagonising the host cell interferon response than Delta variant viruses [9], which provides a mechanistic explanation for the reduced clinical severity of Omicron disease in individuals without pre-existing adaptive immunity [3]. Omicron virus replication was attenuated relative to Delta virus replication in interferon-competent Caco-2 and Calu-3 cells, but not in interferon-deficient Vero cells, and Omicron viruses caused enhanced interferon promotor activity compared to Delta viruses [9]. Additionally, depletion of the pattern recognition receptor MDA5, which plays a critical role in SARS-CoV-2 detection and interferon response initiation [10], resulted in increased Omicron virus replication in interferon-competent cells [9].

The exact molecular reasons for the alleviated interferon response antagonism by Omicron viruses remain to be elucidated. Notably, the Omicron and Delta virus isolates that we investigated (see Suppl. Methods) display sequence variants in the viral interferon antagonists nsp3, nsp12, nsp13, nsp14, the membrane (M) protein, the nucleocapsid protein, and ORF3a [11] (Suppl. Table 1), which may be of relevance. 
Here, we show in addition that two SARS-CoV-2 Omicron isolates (Omicron 1, Omicron 2) replicate to lower titres (Figure 1A) and induce elevated STAT1 phosphorylation (Figure 1B), a key event during interferon signalling, compared to a Delta isolate (B.1.167.2) in Caco-2 and Calu-3 cells [9,12] (see Suppl. Methods for further information).

In A549 cells transduced with ACE2 (SARS-CoV-2 receptor) and TMPRSS2 (mediates SARS-CoV-2 cell entry by cleaving and activating the viral S protein), the Omicron viruses also displayed alleviated infection capacity compared to the Delta virus (Figure 1C). This difference largely disappeared upon depletion of both of the pattern recognition receptors MDA5 and RIG-I that mediate the host cell interferon response in virus-infected cells [13]. However, when we compared interferon activity in the supernatants of SARS-CoV-2-infected cells in a HEK-Blue IFNa/ $\beta$ reporter cell assay, the supernatants of Omicron virus-infected RIG-I-knock out cells induced higher interferon promoter activation than the supernatants of Omicron virus-infected MDA5-knock out cells (Figure 1D). This is in agreement with data showing that MDA5 is primarily responsible for virus recognition and the induction of an interferon response in SARS-CoV-2-infected cells $[10,13,14]$.

Taken together, these findings further confirm that Omicron viruses are less effective than Delta viruses in antagonising the host cell interferon response [9] and that MDA5 is a major player in SARS-CoV-2 recognition $[10,13]$. Accordingly, elevated MDA5 levels were detected in the upper airways of SARS-CoV-2-infected individuals with mild or asymptomatic disease [15]. Since Delta has been found to display a similar level of interferon antagonism and sensitivity as previous SARS-CoV-2 variants $[16,17]$, the reduced interferon antagonism appears to be unique to Omicron. 
Figure 1

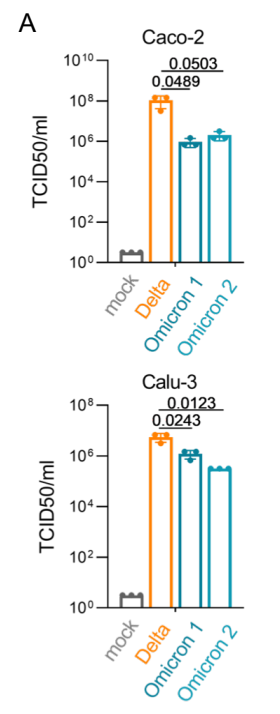

B
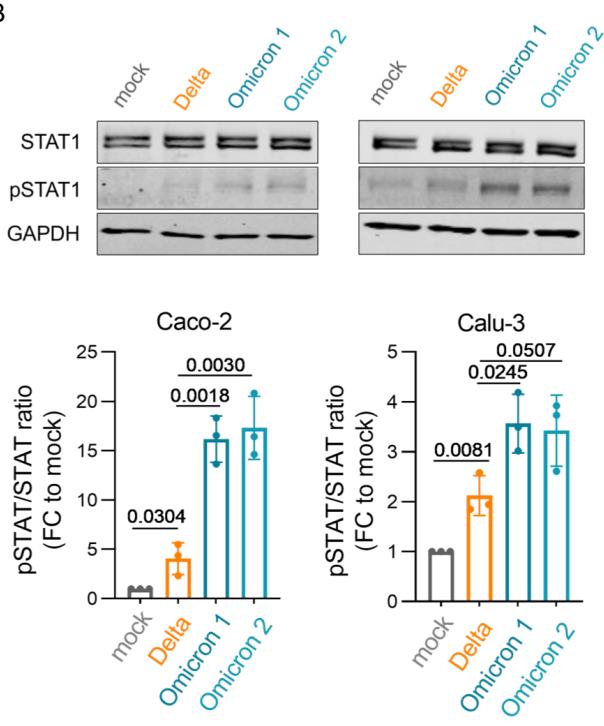

$\mathrm{E}$

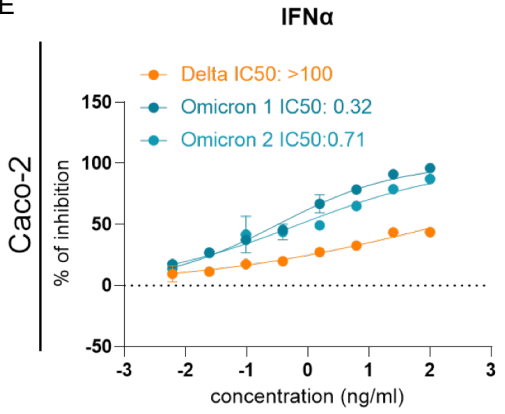

IFNa
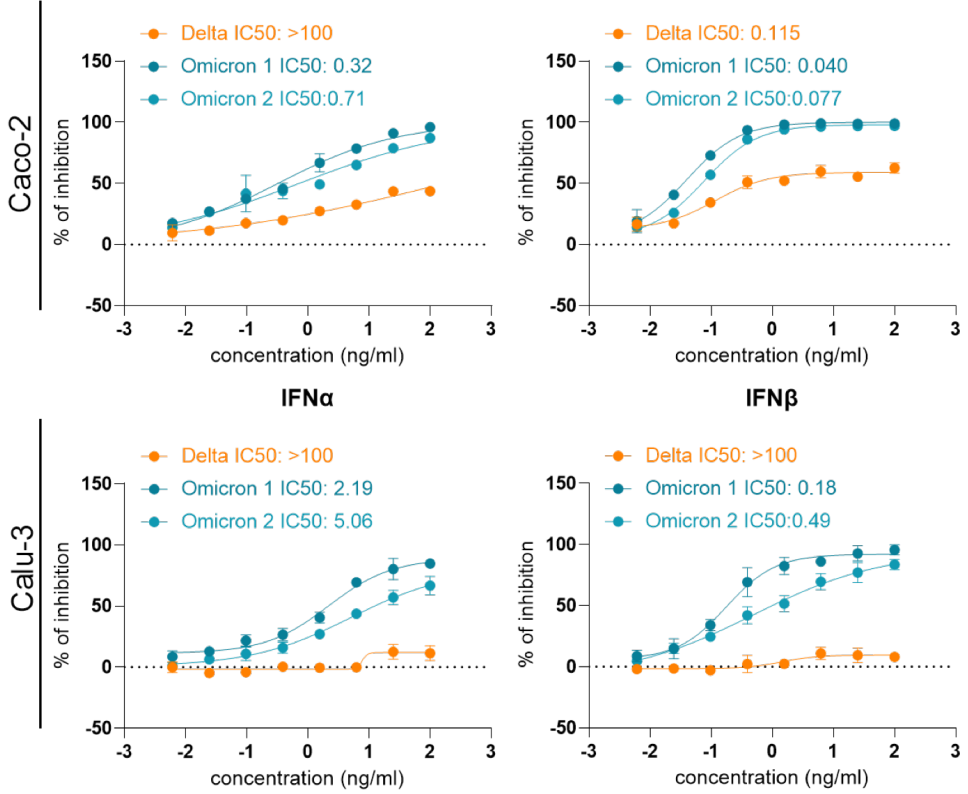

IFN $\beta$

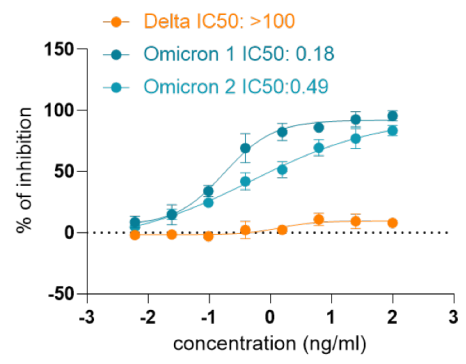

C
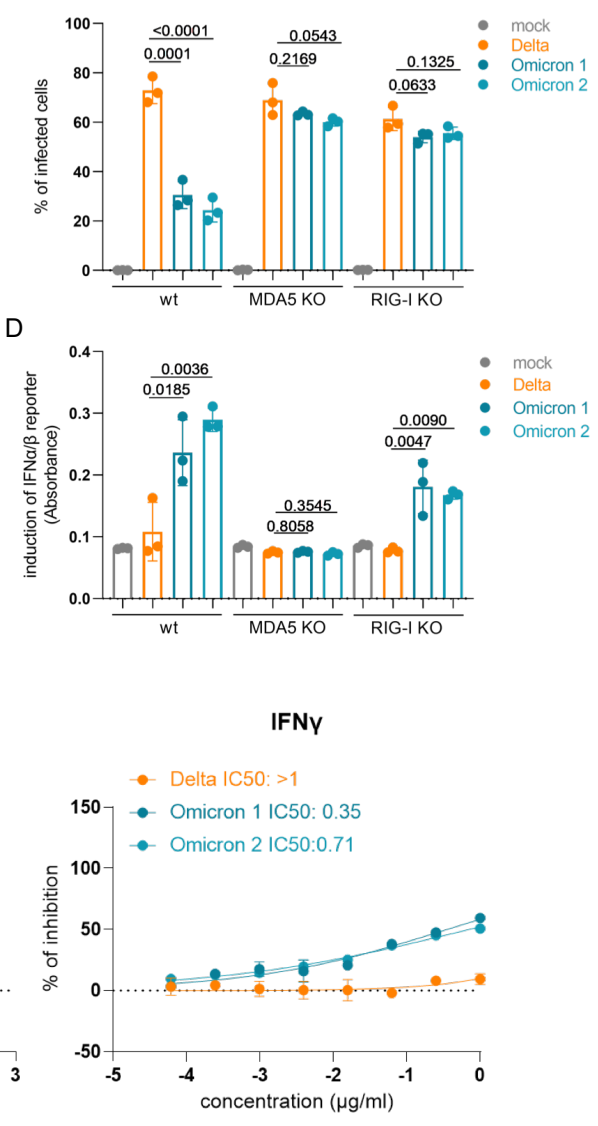

IFNY

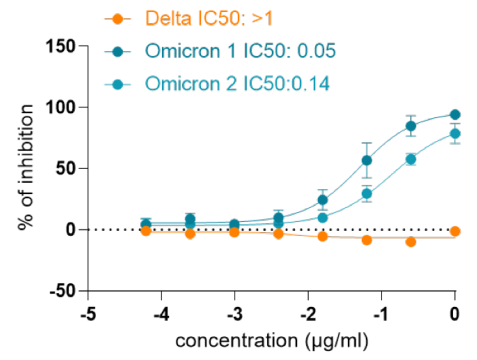

$\mathrm{F}$
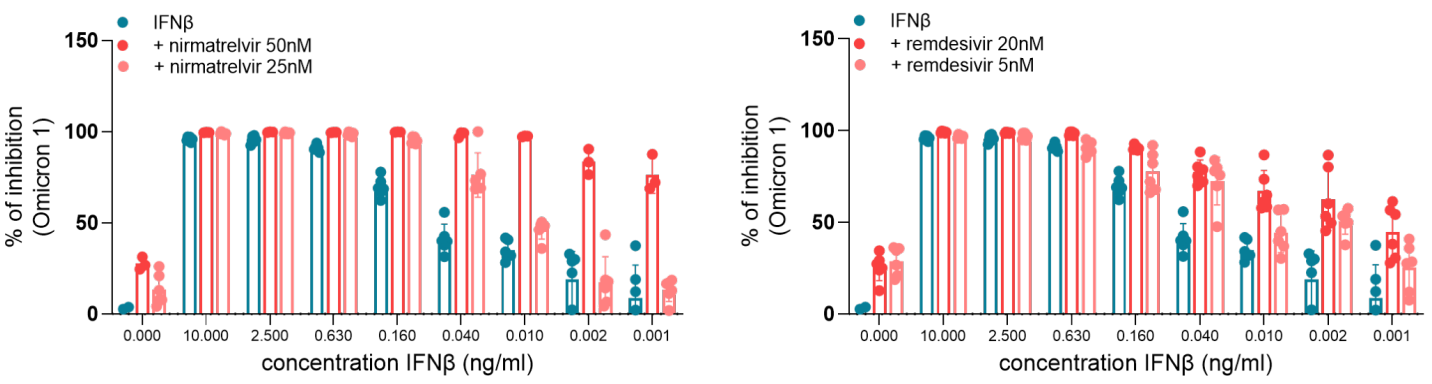

Figure 1 IFN signalling and therapy during infection with novel SARS-CoV-2 variant Omicron. (A) Caco-2 and Calu-3 cells were infected with SARS-CoV-2 variant Delta (GenBank ID: MZ315141), Omicron 1 (GenBank ID: OL800702) and Omicron 2 (GenBank ID: OL800703) at an MOI of 1. The infectious titre was determined $24 \mathrm{~h}$ post infection. Graphs represent mean \pm SD of three biological replicates. P-values were calculated using Student's t test. (B) Immunoblot analysis of total and phosphorylated STAT1. The protein levels were quantified by ImageJ. Graphs represent mean \pm SD of three biological replicates. P-values were calculated using Student's t test. (C) A549-ACE2/TMPRSS2 
MDA5/RIG-I-WT (wt), A549-ACE2/TMPRSS2 MDA5 KO (MDA5 KO) and A549-ACE2/TMPRSS2 RIGI KO (RIG-I KO) cells were infected with Delta, Omicron 1 and Omicron 2 variants at an MOI of 0.01 for $72 \mathrm{~h}$. The number of infected cells was determined by immunofluorescence staining. Graphs represent data of four biological replicates. Statistical testing was performed by one-way ANOVA and Dunn's test. (D) Production of IFNa/ $\beta$ was measured by incubating supernatants from wt, MDA5-KO, and RIG-I KO cells infected with SARS-CoV-2 variants at an MOI of 0.01 for $48 \mathrm{~h}$ using HEK-Blue IFNa/ $\beta$ reporter cells. Graphs displays mean \pm SD of three biological replicates. Statistical testing was performed by one-way ANOVA and Dunn's test. (E) Dose response curves of IFNa, IFN $\beta$ and IFNY was assessed in Caco-2 and Calu-3 cells. All IFNs were added to confluent monolayers and subsequently infected with viral variants at $\mathrm{MOI} 0.01$. The inhibition rate was evaluated $24 \mathrm{~h}$ (Caco-2) and $48 \mathrm{~h}$ (Calu-3) post infection by staining of spike protein. Graphs depicts mean \pm SD of three biological replicates. (F) Antiviral effect of IFN $\beta$ in combinations with nirmatrelvir and remdesivir in Caco-2 cells.

Most notably, treatment with interferon- $\alpha$, interferon- $\beta$, and interferon- $\gamma$ revealed that the weaker interferon antagonism by Omicron virus isolates translates into a profoundly increased Omicron sensitivity to interferon treatment (Figure 1E). Further experiments showed that antiviral interferon- $\beta$ effects were further increased in combination with nirmatrelvir (the antivirally active agent in paxlovid) and remdesivir (Figure 1F). So far, clinical studies reported mixed outcomes in COVID-19 patients treated with different interferons [18-21]. Given the newly discovered substantially increased interferon sensitivity of Omicron viruses, interferons represent a promising option for the treatment of Omicron patients.

In conclusion, we present further evidence that reduced interferon-antagonising activity explains at least in part why Omicron variant infections are inherently less severe than infections with other SARS-CoV-2 variants. Most importantly, we here also show that Omicron variant viruses display enhanced sensitivity to interferon treatment, which makes interferons promising therapy candidates for Omicron patients, in particular in combination with other antiviral agents. 


\section{Acknowledgements}

The authors thank Lena Stegmann, Kerstin Euler and Sebastian Grothe for their technical assistance. This work was supported by the Frankfurter Stiftung für krebskranke Kinder.

\section{Author contributions}

D.B., M.M., and J.C. conceived and designed the study. D.B., T.R., M.N.W., and J.C. performed experiments. All authors analysed data. M.M. wrote the manuscript. D.B., M.N.W., M.M., and J.C. revised the manuscript. All authors have read and approved the final manuscript.

\section{Competing interests}

The authors declare no competing interests. 


\section{References}

1. Abdullah F, Myers J, Basu D, Tintinger G, Ueckermann V, Mathebula M, Ramlall R, Spoor S, de Villiers T, Van der Walt Z, Cloete J, Soma-Pillay P, Rheeder P, Paruk F, Engelbrecht A, Lalloo V, Myburg M, Kistan J, von Hougenhouck-Tulleken W, Boswell MT, Gray G, Welch R, Blumberg L, Jassat W. Decreased severity of disease during the first global omicron variant covid-19 outbreak in a large hospital in tshwane, south africa. Int $J$ Infect Dis. 2021 Dec 28:S1201-9712(21)01256-X. doi: 10.1016/j.jij.2021.12.357.

2. Maslo C, Friedland R, Toubkin M, Laubscher A, Akaloo T, Kama B. Characteristics and Outcomes of Hospitalized Patients in South Africa During the COVID-19 Omicron Wave Compared With Previous Waves. JAMA. 2021 Dec 30. doi: 10.1001/jama.2021.24868.

3. Davies M-A, Kassanjee R, Rosseau P, Morden E, Johnson L, Solomon W, Hsiao N-Y, Hussey H, Meintjes G, Paleker M, Jacobs T, Raubenheimer P, Heekes A, Dane P, Bam J-L, Smith M, Preiser W, Pienaar D, Mendelson M, Naude J, Schrueder N, Mnguni A, Le Roux S, Murie K, Prozesky H, Mahomed H, Rossouw L, Wasserman S, Maughan D, Boloko L, Smith B, Taljaard J, Symons G, Ntusi N, Parker A, Wolter N, Jassat W, Cohen C, Lessells R, Wilkinson RJ, Arendse J, Kariem S, Moodley M, Vallabhjee K, Wolmarans M, Cloete K, Boulle A. Outcomes of laboratory-confirmed SARS-CoV-2 infection in the Omicron-driven fourth wave compared with previous waves in the Western Cape Province, South Africa. medRxiv. 2022 Jan 12: 2022.01.12.22269148. doi: 10.1101/2022.01.12.22269148.

4. Flemming A. Omicron, the great escape artist. Nat Rev Immunol. 2022 Jan 11:1. doi: 10.1038/s41577-022-00676-6. 
5. Bentley EG, Kirby A, Sharma P, Kipar A, Mega DF, Bramwell C, Penrice-Randal R,

Prince T, Brown JC, Zhou J, Screaton GR, Barclay WS, Owen A, Hiscox JA, Stewart JP. SARS-CoV-2 Omicron-B.1.1.529 Variant leads to less severe disease than Pango B and Delta variants strains in a mouse model of severe COVID-19. bioRxiv. 2021 Dec 30. doi: 10.1101/2021.12.26.474085.

6. Diamond $\mathrm{M}$, Halfmann $\mathrm{P}$, Maemura $\mathrm{T}$, Iwatsuki-Horimoto $\mathrm{K}$, lida $\mathrm{S}$, Kiso $\mathrm{M}$, Scheaffer S, Darling T, Joshi A, Loeber S, Foster S, Ying B, Whitener B, Floyd K, Ujie M, Nakajima N, Ito M, Wright R, Uraki R, Li R, Sakai Y, Liu Y, Larson D, Osorio J, Hernandez-Ortiz J, ÄđEiuoderis K, Florek K, Patel M, Bateman A, Odle A, Wong LY, Wang Z, Edara VV, Chong Z, Thackray L, Ueki H, Yamayoshi S, Imai M, Perlman S, Webby R, Seder R, Suthar M, Garcia-Sastre A, Schotsaert M, Suzuki T, Boon A, Kawaoka Y, Douek D, Moliva J, Sullivan N, Gagne M, Ransier A, Case J, Jeevan T, Franks J, Fabrizio T, DeBeauchamp J, Kercher L, Seiler P, Singh G, Warang P, Gonzalez-Reiche AS, Sordillo E, van Bakel H, Simon V. The SARS-CoV-2 B.1.1.529 Omicron virus causes attenuated infection and disease in mice and hamsters. Res Sq. 2021 Dec 29:rs.3.rs-1211792. doi: 10.21203/rs.3.rs-1211792/v1.

7. McMahan K, Giffin V, Tostanoski LH, Chung B, Siamatu M, Suthar MS, Halfmann P, Kawaoka Y, Piedra-Mora C, Martinot AJ, Kar S, Andersen H, Lewis MG, Barouch DH. Reduced Pathogenicity of the SARS-CoV-2 Omicron Variant in Hamsters. bioRxiv. 2022 Jan 3. doi: 10.1101/2022.01.02.474743.

8. Kozlov M. Omicron's feeble attack on the lungs could make it less dangerous. Nature. 2022 Jan 5. doi: 10.1038/d41586-022-00007-8.

9. Bojkova D, Widera M, Ciesek S, Wass MN, Michaelis M, Cinatl J jr. Reduced interferon antagonism but similar drug sensitivity in Omicron variant compared to Delta variant SARS-CoV-2 isolates. Cell Res. in press. 
10. Yin X, Riva L, Pu Y, Martin-Sancho L, Kanamune J, Yamamoto Y, Sakai K, Gotoh

S, Miorin L, De Jesus PD, Yang CC, Herbert KM, Yoh S, Hultquist JF, García-Sastre

A, Chanda SK. MDA5 Governs the Innate Immune Response to SARS-CoV-2 in Lung Epithelial Cells. Cell Rep. 2021 Jan 12;34(2):108628. doi: 10.1016/j.celrep.2020.108628.

11. Wong LR, Perlman S. Immune dysregulation and immunopathology induced by SARS-CoV-2 and related coronaviruses - are we our own worst enemy? Nat Rev Immunol. 2022 Jan;22(1):47-56. doi: 10.1038/s41577-021-00656-2.

12. Wilhelm A, Widera M, Grikscheit K et al. Reduced Neutralization of SARS-CoV-2 Omicron Variant by Vaccine Sera and Monoclonal Antibodies. medRxiv 2021 Dec 13: 2021.12.07.21267432. doi: 10.1101/2021.12.07.21267432.

13. Yang DM, Geng TT, Harrison AG, Wang PH. Differential roles of RIG-I like receptors in SARS-CoV-2 infection. Mil Med Res. 2021 Sep 7;8(1):49. doi: 10.1186/s40779-021-00340-5.

14. Rebendenne A, Valadão ALC, Tauziet M, Maarifi G, Bonaventure B, McKellar J, Planès R, Nisole S, Arnaud-Arnould M, Moncorgé O, Goujon C. SARS-CoV-2 triggers an MDA-5-dependent interferon response which is unable to control replication in lung epithelial cells. J Virol. 2021 Jan 29;95(8):e02415-20. doi: 10.1128/JVI.02415-20.

15. Mohanty MC, Varose SY, Sawant UP, Fernandes MM. Expression of innate immune response genes in upper airway samples of SARS-CoV-2 infected patients: A preliminary study. Indian J Med Res. 2021 May;153(5\&6):677-683. doi: 10.4103/ijmr.IJMR_131_21.

16. Nchioua R, Schundner A, Klute S, Noettger S, Zech F, Koepke L, Graf A, Krebs S, Blum H, Kmiec D, Frick M, Kirchhoff F, Sparrer KMJ. The Delta variant of SARS- 
CoV-2 maintains high sensitivity to interferons in human lung cells. bioRxiv. 2021 Nov 17: 2021.11.16.468777. doi: 10.1101/2021.11.16.468777.

17. Guo K, Barrett BS, Mickens KL, Vladar EK, Morrison JH, Hasenkrug KJ, Poeschla EM, Santiago ML. Interferon Resistance of Emerging SARS-CoV-2 Variants. bioRxiv. 2021 Dec 10: 2021.03.20.436257. doi: 10.1101/2021.03.20.436257.

18. Bhushan B L S, Wanve S, Koradia P, Bhomia V, Soni P, Chakraborty S, Khobragade A, Joshi S, Mendiratta SK, Kansagra KK, Parihar A, Sharma S, Patel J; Study Investigators Group. Efficacy and safety of pegylated interferon-alpha2b in moderate COVID-19: a phase 3, randomized, comparator-controlled, open-label study. Int J Infect Dis. 2021 Oct;111:281-287. doi: 10.1016/j.ijid.2021.08.044.

Bojkova D, Bechtel M, McLaughlin KM et al. Aprotinin Inhibits SARS-CoV-2 Replication. Cells 2020; 9:2377. doi: 10.3390/cells9112377.

19. Li C, Luo F, Liu C, Xiong N, Xu Z, Zhang W, Yang M, Wang Y, Liu D, Yu C, Zeng J, Zhang L, Li D, Liu Y, Feng M, Liu R, Mei J, Deng S, Zeng Z, He Y, Liu H, Shi Z, Duan M, Kang D, Liao J, Li W, Liu L. Effect of a genetically engineered interferonalpha versus traditional interferon-alpha in the treatment of moderate-to-severe COVID-19: a randomised clinical trial. Ann Med. 2021 Dec;53(1):391-401. doi: 10.1080/07853890.2021.1890329.

20. Monk PD, Marsden RJ, Tear VJ, Brookes J, Batten TN, Mankowski M, Gabbay FJ, Davies DE, Holgate ST, Ho LP, Clark T, Djukanovic R, Wilkinson TMA; Inhaled Interferon Beta COVID-19 Study Group. Safety and efficacy of inhaled nebulised interferon beta-1a (SNG001) for treatment of SARS-CoV-2 infection: a randomised, double-blind, placebo-controlled, phase 2 trial. Lancet Respir Med. 2021 Feb;9(2):196-206. doi: 10.1016/S2213-2600(20)30511-7. 
21. WHO Solidarity Trial Consortium, Pan H, Peto R, Henao-Restrepo AM, Preziosi MP, Sathiyamoorthy V, Abdool Karim Q, Alejandria MM, Hernández García C, Kieny MP, Malekzadeh R, Murthy S, Reddy KS, Roses Periago M, Abi Hanna P, Ader F, AlBader AM, Alhasawi A, Allum E, Alotaibi A, Alvarez-Moreno CA, Appadoo S, Asiri A, Aukrust P, Barratt-Due A, Bellani S, Branca M, Cappel-Porter HBC, Cerrato N, Chow TS, Como N, Eustace J, García PJ, Godbole S, Gotuzzo E, Griskevicius L, Hamra R, Hassan M, Hassany M, Hutton D, Irmansyah I, Jancoriene L, Kirwan J, Kumar S, Lennon P, Lopardo G, Lydon P, Magrini N, Maguire T, Manevska S, Manuel O, McGinty S, Medina MT, Mesa Rubio ML, Miranda-Montoya MC, Nel J, Nunes EP, Perola M, Portolés A, Rasmin MR, Raza A, Rees H, Reges PPS, Rogers CA, Salami K, Salvadori MI, Sinani N, Sterne JAC, Stevanovikj M, Tacconelli E, Tikkinen KAO, Trelle S, Zaid H, Røttingen JA, Swaminathan S. Repurposed Antiviral Drugs for Covid19 - Interim WHO Solidarity Trial Results. N Engl J Med. 2021 Feb 11;384(6):497-511. doi: 10.1056/NEJMoa2023184. 